\title{
A integralidade da assistência à criança na percepção do aluno de Graduação em Enfermagem
}

\author{
The integrality of children care in the perception of undergraduate nursing student \\ La atención integral a los niños en la percepción del estudiante de enfermería
}

\section{Maria Cândida de Carvalho Furtado', Liane Cristina Toyonaga Silva', Débora Falleiros Mello', Regina Aparecida Garcia Lima', Mariana Dias Petri', Marina Marques Rosário'}

' Universidade de São Paulo, Escola de Enfermagem de Ribeirão Preto, Departamento de Enfermagem Materno-Infantil e Saúde Pública. Ribeirão Preto-SP, Brasil.

\section{Submissão 03-12-2010 Aprovação: 15-01-2012}

\section{RESUMO}

Estudo de abordagem qualitativa que objetivou identificar como alunos de graduação percebem a integralidade do cuidado da criança no seu processo de aprendizagem, em um Curso de Bacharelado em Enfermagem do interior paulista. Entrevistou-se 89 alunos em junho e dezembro de 2009. Os dados coletados foram analisados mediante análise de conteúdo, sendo identificadas quatro temáticas. A integralidade é vista como cuidado inteiro, envolvendo criança, família, condições de vida, meio ambiente. A instituição de ensino propõe inserção precoce do aluno na realidade; este desmistifica o ideal de cuidado, deparando-se com o real. O professor instiga o aluno a refletir sobre sua prática, para que esta faça sentido e também sejam apreendidos o saber e o fazer relacionado à integralidade do cuidado à criança.

Descritores: Assistência integral à saúde; Criança; Educação em Enfermagem.

\begin{abstract}
This qualitative study aimed to identify how undergraduate students perceive the comprehensive care of children in their learning process in a course of Bachelor of Nursing in São Paulo. We interviewed 89 students in June and December 2009. The collected data were analyzed using content analysis and four themes were identified. Comprehensive care is seen as the entire care, involving child, family, living conditions, environment. The educational institution has proposed early integration of the student in the reality of nursing work; this demystifies the ideal care, and the student faces reality. The professor instigate the student to reflect on their practice, so that makes sense to the student and the knowledge and practice related to comprehensive care to child also be apprehended.
\end{abstract}

Key words: Comprehensive health care; Child; Education; Nursing.

\section{RESUMEN}

Estudio cualitativo sobre como los estudiantes perciben la cuestión de la atención integral a los niños en su proceso de aprendizaje en un curso de Enfermería en el Estado de São Paulo, Brasil. Fueron entrevistados 89 estudiantes en junio y diciembre de 2009. Los datos obtenidos fueron analizados utilizando el análisis de contenido, y se identificaron cuatro temas. La integridad es vista como la atención completa, con participación de los niños, la familia, las condiciones de vida y el entorno. La institución educacional propone la inserción temprana de los estudiantes en la realidad. El estudiante desmitifica el ideal de la atención frente a la realidad. El profesor motiva a los estudiantes a reflexionar sobre su práctica, para que encuentren sentido y también se perciban el conocimiento y las prácticas relacionadas a la atención integral del niño.

Palabras clave: Atención integral de salud; Niño; Educación en enfermería 


\section{INTRODUÇÃO}

A integralidade das ações de saúde no contexto da infância requer que a criança seja entendida como sujeito inserido em um ambiente social e familiar, em constante interação com o meio. Mais do que considerar apenas a doença do indivíduo, a integralidade da atenção envolve o olhar para a pessoa de modo a compreender de forma ampliada o seu contexto de vida. Assim, a preocupação com a pessoa vai além do olhar sobre o biológico, assumindo-se o compromisso de atendê-la em suas múltiplas necessidades ${ }^{(1)}$.

Mediante a escuta, busca-se apreender as necessidades do usuário e assim aumentar, a capacidade e possibilidade dos profissionais de saúde em intervir, uma vez que se preocupam com os problemas que as pessoas demandam aos serviços de saúde ${ }^{(2)}$.

Essa mudança de paradigma, de conceitos e práticas no cuidado à saúde das pessoas também incide na formação de profissionais de saúde, entre eles os enfermeiros, no intuito da ampliação do conceito de cuidado a ser prestado(3).

As transformações curriculares ocorridas a partir de 2001 com as Diretrizes Curriculares Nacionais para os Cursos de Graduação em Enfermagem (DCENF) estabelecem novas competências e habilidades que deverão ser desenvolvidas pelos estudantes durante seu processo de aprendizado ${ }^{(4)}$. Essa implantação implica no desafio de formar profissionais com competência técnica e política, considerando-os sujeitos sociais que possuem conhecimento, raciocínio, percepção e sensibilidade, tendo ainda a instituição formadora o compromisso de capacitação dos alunos para intervir em diversos contextos de cuidado à saúde, sendo estes, muitas vezes, incertos e complexos ${ }^{(5)}$.

A implantação da nova estrutura curricular no Curso de Graduação em Enfermagem da escola cenário de estudo desta investigação iniciou em 2005, tendo como base as DCENF. A instituição apresenta um Projeto Político Pedagógico que intenciona contribuir para a consolidação do Sistema Único de Saúde (SUS) e de seus princípios, como também diretrizes orientadoras apoiadas na universalidade, eqüidade, integralidade da atenção e participação social do usuário ${ }^{(6)}$.

Os alunos vivenciam desde o primeiro ano do curso o contato com a prática profissional em Unidades de Saúde da Família (USF) e Unidades Básicas de Saúde (UBS), com visita domiciliar, observação da atuação dos profissionais de saúde da atenção básica e início do contato com os usuários dos serviços de saúde. No segundo ano, nas UBS, são mantidas as visitas domiciliares e os alunos iniciam consultas de enfermagem e procedimentos técnicos dentro das unidades de saúde como coleta de sangue, imunização e medicação, passando nos anos subseqüentes a atuarem no cuidado clínico ao paciente hospitalizado. Em todas as oportunidades de aprendizado, o aluno é estimulado quanto ao desenvolvimento de suas habilidades cognitivas, conceituais e procedimentais, como também é instigado a pensar o cuidado prestado de modo crítico e reflexivo, quer seja ele individual ou voltado à comunidade. Frente a essa realidade de aprendizado vivenciada pelo graduando de enfermagem, o presente estudo objetivou descrever como os alunos percebem a integralidade do cuidado prestado à criança no seu processo de aprendizagem, em um Curso de Bacharelado em Enfermagem do interior do estado de São Paulo.

\section{PERCURSO METODOLÓGICO}

Trata-se de estudo descritivo com abordagem qualitativa ${ }^{(7)}$ que buscou descrever e explorar a compreensão acerca da integralidade do cuidado da criança em dois períodos distintos de aprendizado durante um Curso de Bacharelado em Enfermagem do interior do estado de São Paulo.

Participaram do estudo 89 alunos de Graduação em Enfermagem que cursaram disciplinas envolvendo o cuidado da criança no segundo e terceiro anos do curso. No segundo ano, os alunos possuem como campo de ensino teórico-prático as USF e UBS, realizando consultas de puericultura e visitas domiciliares às crianças e suas famílias. Já no terceiro ano, os alunos realizam suas atividades com neonatos, crianças, adolescentes e suas famílias no contexto hospitalar (Clínica Pediátrica e Unidade de Cuidado Intermediário Neonatal - UCIN). Buscamos, portanto, a percepção dos alunos em distintos cenários de aprendizagem.

Os dados foram coletados em dois momentos, junho e dezembro de 2009, ao término de cada disciplina, mediante preenchimento de um questionário pelo próprio aluno, entregue em sala de aula, com questões abertas sobre o conceito de integralidade do cuidado da criança, o preparo teórico para tal conceito, exemplo(s) de integralidade do cuidado da criança na prática vivenciada durante o ensino teórico prático e a percepção sobre a prática da integralidade do cuidado da criança nos serviços de saúde.

O estudo foi aprovado pelo Comitê de Ética em Pesquisa da própria instituição (protocolo $n^{\circ}$ 106/2009), o sigilo dos dados dos participantes foi resguardado seguindo as diretrizes que regulamentam pesquisas envolvendo seres humanos ${ }^{(8)} \mathrm{e}$ os alunos assinaram o Termo de Consentimento Livre e Esclarecido. Utilizamos a letra "I" para os alunos do segundo ano e a letra " $C$ " para os alunos do terceiro ano. Estas letras foram seguidas por números que representam o total de sujeitos participantes do estudo.

O questionário foi testado previamente quanto ao tempo de resposta e adequabilidade, compreensão e clareza das perguntas e respostas por dois alunos de cada ano, não havendo necessidade de alterações no planejamento inicial. Para análise dos dados, cada sujeito da pesquisa foi considerado como uma unidade e, portanto, as respostas de cada sujeito foram codificadas de forma padronizada e na seqüência formaram-se categorias de maior abstração. A partir da leitura exaustiva do material empírico, procuramos encontrar palavras e frases que se repetiam ou que se destacavam, no intuito de elucidar aspectos relacionados ao tema integralidade do cuidado da criança ${ }^{(7)}$.

\section{RESULTADOS E DISCUSSÃO}

Com relação à caracterização dos alunos, 95,5\% são do sexo feminino. A idade média dos participantes foi 20 anos no 
segundo ano e 22 anos no terceiro ano. Como local de ensino teórico prático, $43 \%$ dos alunos do segundo ano atuaram em UBS e $57 \%$ em USF; $60 \%$ dos alunos do terceiro ano tiveram como campo de atuação UCIN e 40\% Clínica Pediátrica.

A partir das leituras do material empírico, foram identificadas quatro temáticas acerca da percepção do aluno de graduação sobre a integralidade do cuidado da criança: "Conceituando integralidade do cuidado", "O ensino da integralidade do cuidado", "A integralidade do cuidado na prática do aluno de graduação" e "A integralidade do cuidado da criança nos serviços de saúde".

\section{Conceituando integralidade do cuidado}

Com relação ao conceito de integralidade, grande parte dos alunos, tanto do segundo como do terceiro ano, considera que seja um olhar voltado aos aspectos bio-psico-socio-cultural-espiritual da criança e de sua família, revelando que essa integralidade:

[...] significa um olhar minucioso sobre as condições biológicas da criança e uma observação abrangente sobre as condições de vida, psicossociais, família com quem essa criança crescerá e se desenvolverá. (I3)

[...] compreende tanto os cuidados biológicos/fisiológicos, atendendo tanto as necessidades básicas de saúde, quanto tudo que interfere no seu crescimento e desenvolvimento abrangendo fatores sociais, espirituais, familiares e psicológicos. (C27)

Também ressaltam, em maior frequência, a concepção de um cuidado para além da doença, do físico, considerando o meio em que a criança vive e sua relação com o mesmo.

Cuidar da criança de forma integral, não olhando apenas para a doença e sim para a realidade em que a criança está inserida e tudo que possa influenciar na saúde dessa criança. (I10)

Entendo que devemos focar o cuidado não apenas na criança no contexto hospitalar e na doença atual, no físico, mas também na condição social em que vive, nos problemas do resto da família e as conseqüências que a doença da criança causa à família (separação, financeiros, ....). (C6)

Dentro dessa concepção de cuidado integral, os alunos refletem acerca das relações causais envoltas no processo saúde doença e que necessitam ser consideradas ao olhar a criança como um todo.

Entendo que prestar um cuidado integral requer que nós olhemos não somente para o $R N$, mas para o ambiente como influenciador no processo saúde doença e também para a mãe. Quando falo em ambiente, me refiro aos aspectos sociais, econômicos e culturais. (C37)

Mais que um princípio do SUS, a integralidade possui a capacidade de permitir uma identificação dos indivíduos como totais, mesmo que não seja possível alcançar toda a plenitude, ao considerar as dimensões a que este sujeito encontra-se relacionado ${ }^{(9)}$.

Este olhar ampliado a que se referem em sua concepção de cuidado integral, revela uma assistência que também envolva as pessoas que convivem com a criança, ou seja, os pais e/ou cuidadores.

É o cuidado não apenas da saúde da criança, mas dela como um todo, de sua relação com os pais, de sua convivência em casa, não focalizando apenas um problema fisiológico. (141)

Cuidar da criança-sujeito e da sua família. A atenção dada à saúde da criança também deve ser dada às dúvidas e medos dessa família. (C22)

Na perspectiva do cuidado integral da criança, o indivíduo é visto como uma integração biopsicossocial; um social amplo, compreendendo o meio em que esta criança vive, com uma integração que viabilize a apreensão da subjetividade da criança e suas relações com a mãe, família e comunidade ${ }^{(10)}$.

Ainda que em uma frequência não muito elevada, algumas falas se destacam, ao apresentar uma definição em que a proposta está na integração de conhecimentos, com a multidisciplinaridade como parte importante do processo de cuidar da criança.

Deve ser um cuidado integral, prestado por uma equipe qualificada, multiprofissional e integrada a fim de garantir ao cliente (neste caso a criança) a melhor assistência possível capaz de suprir as necessidades do indivíduo, mas sem esquecer a importância da família como cuidadora e como base estrutural para o desenvolvimento da criança. (I21)

A integralidade do cuidado também é vista como um direito da criança, respeitando-se a particularidade de cada fase do desenvolvimento.

É reconhecer a criança com um cidadão que necessita de cuidados envolvendo todos os aspectos biopsicossociais; com direitos e deveres e que deve ser cuidada e pensada como agente ativa do cuidado em saúde. (144)

Entender a criança como um ser individual, dotado de direitos e particularidades, e não alguém só em formação. (C3)

A integralidade é vista como a transcendência de um cuidado somente organizacional, preso à hierarquização e regionalização da assistência à saúde; é um cuidado que se sedimenta na qualidade da atenção ao indivíduo e ao coletivo como direito assegurado ${ }^{(9)}$.

\section{O ensino da integralidade do cuidado}

O ensino do cuidado integral da criança, foco de interesse no presente estudo, é revelado pelos dois grupos com forte tendência ao tipo de formação proposta pela instituição de ensino, 
cenário desse estudo. $\mathrm{O}$ aluno vivencia, na realidade do mundo do trabalho, questões que emergem para a reflexão da e na ação, num movimento de aprendizado que requer que o aluno mobilize conhecimentos adquiridos previamente e, até mesmo, aqueles apreendidos durante seu processo de aprendizagem.

Esta proposta, implantada em 2005(6), fundamenta-se nos eixos da atenção primária à saúde, processo saúde doença/ cuidado, processo de trabalho pautado na produção de cuidado, utilizando o referencial pedagógico da competência dialógica, envolvendo a interdisciplinaridade e temas que permeiam o ensino de enfermagem e se cruzam no sentido de favorecer o cuidado, como ética, trabalho em equipe e humanização ${ }^{(11)}$.

Nas disciplinas que envolvem o cuidado ao indivíduo e comunidade, as aulas tornaram-se mais dinâmicas, menos expositivas, sendo que o aluno muitas vezes vivencia primeiro a realidade e depois a discute, em pequenos grupos, buscando subsídios teóricos no sentido de melhor apreendê-la.

A faculdade estimula o aluno a prestar o cuidado integral fornecendo conteúdo teórico e estimulando-o a vincular o teórico com a prática. (C1)

Acho que nosso currículo, nossa formação, tem significativa contribuição para desenvolvermos uma assistência integral. (C3)

Durante todo o curso, desde o primeiro ano, esse conceito de integralidade nos é passado para entendermos a real necessidade e a diferença que esse tipo de cuidado faz durante o cuidado dos pacientes. (C7)

Essa formação, voltada ao mundo do trabalho, em busca de um profissional, capaz de responder às situações vivenciadas de modo crítico e reflexivo, envolve a inserção do aluno na prática profissional o mais precoce possível ${ }^{(6,11)}$, com vistas a preparar um novo profissional, um indivíduo com espírito crítico, um cidadão preparado para aprender a criar, a propor, a construir ${ }^{(12)}$.

O processo ensino aprendizagem da integralidade do cuidado está vinculado, aos olhos dos alunos, à teoria apresentada em sala de aula, aos estudos/leituras realizados, mas também se relaciona à presença não somente do professor/ facilitador, como também do profissional de saúde enfermeiro que atende à criança.

As aulas teóricas deram uma base para podermos realizar a assistência, mas me senti mais preparada por estar na presença da professora e ela realizou tudo juntamente com as alunas. (15)

[...] além da aula teórica tive uma ótima orientação da enfermeira da unidade de saúde, o que foi fundamental para minha prática. (143)

Creio que pela presença da professora no auxílio/supervisão pude visualizar a criança como um todo, pois a mesma instigava o olhar de todos os aspectos. (C35)
O professor é mediador do conhecimento e facilita o aprendizado do aluno, indicando caminhos para que o mesmo consiga construir conhecimentos e intervir na realidade ${ }^{(11)}$.

Alguns alunos do segundo ano colocaram a sensação de ainda não se sentirem preparados para a assistência à criança, pois como essa foi sua primeira vivência prática no cuidado da criança; apenas observaram o que foi realizado. Entretanto, destacam como importante a presença do professor no cenário, como facilitador desta aprendizagem.

Por ser a primeira vez que estava realizando assistência à criança, senti que o nosso primeiro passo era observar a conduta da nossa professora, para saber como conduzir essa assistência e por onde e em que parte começarmos. Logo, sem apoio da docente não desenvolveríamos a prática. (113)

Espera-se que o aluno, ao entrar em contato com a realidade do cuidado, demonstre habilidade prática que se associa ao seu conhecimento teórico. Esse momento é considerado como tenso, incerto, inseguro. O ambiente, nesse caso, o cenário de ensino teórico prático é novo aos olhos do aluno, e o fato do encontro com uma pessoa desconhecida, o paciente (no caso, a criança), exige que o aluno tenha habilidade para lidar com suas emoções e também com as do outro(13). Para que tal encontro torne-se um momento de crescimento do aluno no sentido de seu aprendizado é preciso que o professor atue muito próximo, permitindo que o aluno se sinta envolvido e apoiado com relação ao cuidado prestado, num movimento de aprendizado baseado em trocas ${ }^{(13)}$.

O exercício de vivenciar a prática para, a partir dela, problematizar a realidade, aprender com ela e nela intervir é um aspecto considerado no currículo de Enfermagem da instituição cenário desse estudo. As falas de alguns alunos destacam que essa visão ainda não é compartilhada por todos. Com relação a sentir-se preparado para a prática da integralidade, eles comentam que:

Não. Pois eu precisei estar presente nos campo de imersão sem anteriormente ter estudado a teoria sobre a saúde da criança. Eu sabia apenas o básico e como eu deveria me portar e agir diante minhas dúvidas. (I18)

Não. Pois fui para o cenário de prática sem aprender a teoria, e, portanto aprendi as questões mais relevantes da assistência à criança neste cenário. (I37)

A sensação de despreparo para atuar na prática, muitas vezes, advém da vivência prévia em uma metodologia tradicional de ensino, baseada na transmissão do conhecimento, e que muitas vezes limita o aluno a abrir-se para o novo. Ao primeiro contato, os alunos sentem dificuldades em compreender a proposta de construção de conhecimento e participação ativa nessa construção ${ }^{(11)}$.

Tais sentimentos não aparecem nas falas dos alunos do terceiro ano, que já tiveram contato com inúmeras disciplinas clínicas e que se familiarizaram com o modelo de 
aprendizagem baseado na vivência prática como problematizadora do aprendizado.

A experiência da prática assistencial aparece nas falas dos alunos do terceiro ano como forma de complemento ao que aprenderam teoricamente e vice e versa; desse modo, acerca de seu preparo para o cuidado integral, referem que:

Sim. A partir das oportunidades que o campo de imersão nos proporciona, foi bem tranqüilo relacionar a teoria com a prática. (C29)

Sim, foi possível aplicar os conhecimentos de aprendizagem e surgiram oportunidades de dar uma assistência em todos os aspectos para os bebês. (C30)

Esse contato com a prática leva à evolução do conhecimento do aluno, o que o torna mais apto a prestar um cuidado ampliado, mesmo para aqueles que têm seu primeiro contato com a assistência à criança.

No início tive bastante dificuldade para lidar com as crianças e também não tinha uma visão bem direcionada, mas no final do estágio já tinha condições de tentar promover uma boa assistência devido às experiências que passei. (I3)

Na medida em que os estágios corriam, havia maior conhecimento e preparação para o desenvolvimento das práticas junto à criança. Também, através das aulas teóricas, pudemos aprimorar toda a prática e conhecimento a ser prestado. (114)

A instituição, cenário desse estudo, como anteriormente mencionado, utiliza o referencial pedagógico da competência dialógica. Nesse sentido, pretende-se um profissional que perceba e interaja com a realidade que vivencia e que reflita sobre o mundo. Isso implica em conhecer o mundo de maneira interativa, com capacidade de articular e organizar todos os elementos e informações sobre o mesmo, para perceber a realidade que hoje se caracteriza como global, multidimensional e complexa ${ }^{(14)}$. Significa que o conhecimento necessita ser construído dentro de uma perspectiva relacional e reflexiva, entre sujeito e mundo, com articulação dos múltiplos elementos sociais, políticos, econômicos, históricos, afetivos e psicológicos ${ }^{(14)}$.

Apesar de as falas caminharem para a percepção de que a prática do cuidado integral da criança é algo que se adquire com um currículo que viabilize esse olhar, com preparo e com tempo, há que se considerar também o cenário de ensino teórico prático como facilitador ou dificultador de tal aprendizagem. Nesse sentido, algumas limitações para atuação de um modo integral são reveladas pelos alunos.

Acho que nosso currículo, nossa formação, tem significativa contribuição para desenvolvermos uma assistência integral. Porém, apesar de preparados, ainda encontramos dificuldade e resistência em aplicá-los na prática, onde nossa atuação ainda é limitada à assistência de rotina do local.
Se a unidade de estágio oferece um ambiente onde tem uma assistência integral e humanizada, nós nos inserimos neste contexto. Enquanto num cenário mais "tradicional" e clínico, nossa intervenção, apesar das intervenções "amplas" e holísticas, se restringem ao que já é feito lá. (C3)

No primeiro e segundo ano foi "batido" o conceito de integralidade, em ver o paciente holisticamente. O problema é na prática, como o aluno vai ter um cuidado integral em campos que priorizam o biológico?(C31)

A construção da integralidade na formação do enfermeiro envolve assumir a ação em saúde como um princípio educativo, em um modelo novo em que o aprender e ensinar saúde rompem com o saber formatado e descontextualizado ${ }^{(2)}$; é preciso que o ensino esteja voltado para a valorização tanto dos aspectos clínicos, como dos relacionados ao contexto em que o sujeito vive ${ }^{(15)}$

Nessa modalidade de ensino aprendizagem é preciso oportunizar ao aluno o desenvolvimento da capacidade de agir com eficácia frente às mais diversas situações, tendo como base conhecimentos adquiridos previamente, porém não se limitando a estes ${ }^{(16)}$. De acordo com as autoras, faz-se necessária a aquisição de competências, ou seja, a capacidade de utilizar os conhecimentos adquiridos e integrá-los ou mobilizá-los, visando sua resolução; refere-se ao saber agir e transformar a prática, num processo de reflexão crítica do aprendizado e intervenção efetiva na prática do cuidado(16).

\section{A integralidade do cuidado na prática do aluno de graduação}

Os alunos foram questionados se conseguiram aplicar na prática assistencial, durante seus estágios, um cuidado integral à criança. Os exemplos variaram, pois os alunos do segundo ano trouxeram exemplos a partir da observação. Nesse momento de aprendizagem teórico prática, muitas vezes o aluno participa do cuidado juntamente com o professor/facilitador ou com o enfermeiro assistencial.

Durante as consultas de enfermagem (puericultura) a professora abordou todos os aspectos do desenvolvimento da criança. Realizou o exame físico completo, orientando a mãe quanto à situação da diarréia, doença respiratória, etc. Sempre pediu para observar o cartão de vacina, perguntava como estava o padrão de eliminação da criança, se ela estava se alimentando bem. (I4)

A visita domiciliar exemplificada pelos alunos desse mesmo ano revela-se um importante instrumento de obtenção de dados que amplia o olhar para as questões da saúde da criança e família.

Uma visita domiciliar a uma mãe que não fazia acompanhamento no serviço, morando em condições precárias, muito possessiva com a filha a ponto de não dormir mais com o marido e de dizer que não deixará a filha freqüentar a escola; alimentação também precária e higiene quase inexistente com a casa cheia de animais. (I3) 
Realizei uma visita domiciliar para uma criança de dois meses para avaliar seu desenvolvimento, mas quando cheguei à casa da família havia mais três crianças (todos meninos) que brigavam muito para chamar a atenção da mãe, por ciúmes, pois a mãe naquele momento necessitava dar mais atenção à menina que possuía apenas dois meses, fiquei sem jeito para lidar com essa situação. (I8)

A visita domiciliar possui importância como "espaço privilegiado para diálogo e produção de saberes", com possibilidade de encontros entre o conhecimento leigo e o acadêmico, que aproxima o profissional de saúde da família e da realidade em que esta se encontra(17).

Historicamente, é um instrumento utilizado pela enfermagem de saúde pública quando o foco da atenção é a família. Redefinida nos tempos atuais, a visita domiciliar apresenta-se com uma abordagem ampliada, com o propósito de extensão das ações de saúde à população, dentro de um contexto social $^{(18)}$. Acresce-se, ainda, a importância do exercício competente dos profissionais para a sua realização, como também o compromisso das instituições formadoras com a valorização e inserção desse conteúdo durante o aprendizado do graduando em Enfermagem ${ }^{(18)}$.

Os alunos do terceiro ano possuem maior autonomia em sua inserção no cenário de aprendizado teórico prático; eles cuidam diretamente da criança e família, com supervisão e auxílio do professor/facilitador. Nesse sentido, suas respostas acerca da aplicação prática do conceito de integralidade retratam ações realizadas por eles mesmos.

Na UCIN a mãe do lactente que ficou sob os meus cuidados, era usuária de drogas e foi preciso fazer uma abordagem sobre essa questão com a mãe do bebê e a família. (C1)

A cuidadora do meu paciente não sabia ver horário no relógio, nem utilizar termômetro, além do baixíssimo conhecimento geral. Foram necessárias orientações básicas a essa mãe para que o cuidado a essa criança em tratamento quimioterápico tivesse uma continuidade em casa. (C23)

As ações ampliadas do cuidado são percebidas pelos alunos que relatam os resultados que obtiveram a partir de um olhar mais atento às reais necessidades da criança ou da família. Muitas vezes, o problema não estava relacionado ao cuidado do físico, da doença, mas apresentava-se como um fator de interferência na condição de saúde da criança ou da família.

No estágio realizado na maternidade, a mãe do $R N$ estava muito nervosa e ansiosa para ir embora de alta, e isso estava influenciando nos cuidados e amamentação com o bebê. Consegui dar orientações e conversar com a mãe e o pai do RN, acalmando-os e melhorando a amamentação. (C30)

Cuidei de uma criança com câncer e seu estado de saúde piorava quando seu pai se alterava emocionalmente; aí vi a importância do apoio emocional a este pai. (C33)
O paciente que acompanhei era muito tímido e estava acompanhado pela avó. Trabalhamos com ele e com a acompanhante e ele agora está mais comunicativo e relacionando-se melhor com ela. (C36)

Todas as falas contêm a execução de um cuidado ampliado, aberto a todas as questões que envolvem a criança, transpondo o biológico, inserindo a família nesse cuidado. Incentivar a participação e o envolvimento da família no cuidado, identificando o papel que esta assume no processo saúde/ doença/cuidar, apresenta extrema relevância, uma vez que ao pensar em assistir a criança de uma maneira mais ampla, busca-se também perceber a sua família como parte de todo o contexto que envolve esse paciente ${ }^{(19)}$.

Os alunos revelam também aspectos voltados à avaliação familiar como forma de obter informações relevantes e que auxiliem o cuidado da criança.

Associar o fato de a criança estar sempre resfriada com a mania de limpeza da mãe que está sempre lavando tudo e deixando o chão molhado ou dando vários banhos por dia na criança, na água fria, dentro do tanque, ao menor sinal de sujeira. (I5)

[...] quando coletávamos dados sobre a família, as condições socioeconômicas e o contexto da família, pois consideramos estes aspectos relevantes para a prestação de uma assistência adequada. (C38)

Apesar das falas acima demonstrarem a importância da avaliação familiar para compreender seu funcionamento e trazer subsídios para melhora e ampliação do cuidado, um aluno revela sua frustração ao coletar os dados, compreender sua importância, porém, não conseguir registrá-los por não haver local usualmente utilizado para tal fim.

No sétimo andar da Pediatria fizemos uma avaliação familiar da criança, identificando a participação e envolvimento da mãe, dos irmãos, do pai, o que a criança entende por família, e no prontuário quando fomos passar para a anotação de enfermagem, fomos ensinadas até que não era para colocar essas informações nas anotações de enfermagem que isso era bom sabermos, mas desnecessário anotar. $E$ não havia nenhum instrumento ou formulário em que pudessem ser anotadas essas informações. Nos pareceu paradoxal termos uma aula na disciplina sobre abordagem familiar se somos censuradas na prática. (C3)

O registro de enfermagem, forma de comunicação escrita acerca das informações relativas ao paciente e seu cuidado, deve conter os elementos necessários que subsidiam e facilitam a coordenação e a continuidade do planejamento da assistência. De modo claro, conciso e completo, as informações viabilizam o monitoramento, planejamento e avaliação contínua do cuidado ${ }^{(20)}$.

A impossibilidade de registrar um dado, como no relato acima, impede a transmissão de informações para toda a 
equipe responsável pelo cuidado da criança e família, fazendo com que os dados, possivelmente, se percam e com que o aluno não incorpore a intencionalidade e importância da coleta e registro completos dos dados acerca do paciente e família para o planejamento da assistência de enfermagem.

Ainda com relação ao cuidado integral da criança durante a prática assistencial aparece, nas falas dos alunos, a articulação da equipe de saúde para resolução de necessidades identificadas e o reconhecimento da importância da atenção multiprofissional.

No Núcleo de Saúde da Família, as famílias recebiam visitas e compareciam às consultas de enfermagem e médica. E todos os casos eram discutidos pela equipe a fim de proporcionar um cuidado integral às mesmas. (I12)

Vivenciei recentemente a situação de um RN que foi encaminhado a UCIN devido à prematuridade e icterícia precoce. Após a resolução do quadro clínico, outra questão apontou: questões sociais. A mãe tinha 16 anos, baixa produção de leite e o pai 19 anos, moravam sozinhos em uma casa emprestada sem condições de saneamento básico e acesso restrito (zona rural). Foi muito interessante observar o trabalho da assistente social e a preocupação da enfermeira em providenciar um ambiente melhor a este $R N$. Além da responsabilidade de encaminhar este bebê com a garantia de que ele irá ser assistido pelo serviço de saúde local. (C29)

Há, portanto, que se valorizar a integração entre as equipes de saúde que assistem a criança, como modo de estimular os profissionais a ampliarem sua visão acerca do cuidado e viabilizarem meios de desenvolver modelos assistenciais que tenham a família como foco de atenção ${ }^{(19)}$.

\section{A integralidade do cuidado da criança nos serviços de saúde}

O último tema refere-se à realidade da prática assistencial da integralidade nos serviços de saúde. Ao serem questionados se a instituição em que realizaram seu aprendizado teórico prático promove a integralidade da assistência à criança, a maioria dos alunos respondeu que, em sua opinião, a instituição promove um cuidado parcial.

Os alunos percebem a prática a partir do momento que a observam, vivenciam, interagem com a equipe e discutem com o professor e com os colegas os aspectos relacionados às questões que impedem uma atuação mais ampla no cuidado da criança. Tais questões envolvem não somente o cuidado com o aspecto biológico, mas também a atuação do profissional de saúde em oposição ao cuidado integral quer seja individualmente ou mesmo em equipe.

Em uma das unidades de saúde isto foi mais visível do que na outra, na qual era realizado o serviço de pré-consultas por uma técnica de enfermagem que apenas pesava, media e organizava as fichas para a consulta médica. (16)

No estágio, presenciei dois partos. Em um, o RN foi colocado junto à mãe logo após o nascimento e depois os cuidados foram feitos por nós e pela enfermeira da Escola (supervisora). Num segundo momento, outro RN foi entregue ao pai somente no final dos cuidados, após ser vestido. Então conclui que é uma atitude que está associada ao profissional que realiza os cuidados, ao conceito que ele tem de humanização e assistência integral e não é uma conduta padrão, norma do local. (C3)

Outros alunos visualizam uma atitude positiva na atenção prestada pelo profissional de saúde, que vai ao encontro do que eles percebem ser o caminho para uma assistência integral à criança.

Os profissionais, principalmente as enfermeiras, me pareceram participar e promover, como um todo, a assistência à criança, dispensando tempo e cuidado às questões do cuidado tanto biológico como social das crianças, envolvendo-se com cada caso e tentando resolver da melhor maneira os problemas dessa criança. (C7)

O cuidado tem relação próxima à sensibilidade que possui o cuidador, pois se este não apresentar tal característica, muito se perderá da oportunidade de perceber o que realmente acontece com aquele que depende de seu cuidado ${ }^{(21)}$.

A preocupação, por partes de alguns profissionais, com o cumprimento de tarefas relacionado ao cuidado aparece como um fator que interfere no modo de cuidar da criança, pois para os alunos, essa ação fragmentada está aquém do que é preciso para atender integralmente a criança.

Vejo parcialmente. Os profissionais de saúde realizam seu trabalho, muitas vezes apenas por realizar seu trabalho, não visando uma boa assistência à criança, visando apenas finalizar suas tarefas. (C26)

Acho que muitas vezes o profissional dá muito mais importância à realização de sua tarefa no plantão e deixa de lado a assistência voltada para o RN e família, mais simples que procedimentos realizados. (C28)

É preciso considerar que o cuidado não diz respeito apenas à aplicação das técnicas de enfermagem; envolve a ajuda ao paciente no sentido de enfrentar os problemas atuais, com inserção também da família nesse enfrentamento ${ }^{(21)}$.

A predominância do aspecto biológico surge como justificativa para o cuidado parcial prestado à criança pela instituição.

[...] nem todas as unidades de saúde onde passei abrangem um olhar mais amplo que o biológico, deixam de lado a parte psicossocial da família. (13)

Percebo que ainda predomina o enfoque biológico do cuidado. Não significa que os outros aspectos não são percebidos, mas, às vezes, negligenciados ou pouco valorizados. (C2) 
Partindo do olhar somente para o biológico, algumas falas apontam para a divisão do trabalho, a fragmentação do cuidado da criança como formas de não integralidade do cuidado.

Muitas vezes o cuidado é dividido entre vários profissionais, o que prejudica o cuidado integral da criança. (C33)

Um funcionário da enfermagem ficava responsável pelos cuidados e outro pela medicação, e no meu ponto de vista isto não é focar a integralidade. (C36)

Favorecer a integralidade envolve um fazer mais amplo, um atendimento desfragmentado no qual os profissionais mantenham uma relação com os sujeitos como seres humanos e não como objetos ${ }^{(22,23)}$.

Além da percepção relacionada ao cuidado prestado pelo profissional, os alunos apontam aspectos da própria instituição de saúde (UBS, USF, hospital) que facilitam o cuidado integral da criança.

A instituição promove consultas de puericultura, visitas domiciliares e discussão dos casos, visando sempre observar aspectos do desenvolvimento e crescimento da criança, dando orientações e informações para melhorar e conservar a saúde da criança. (14)

Também notei que o hospital dá subsídios para que essa assistência seja integral, como acesso a diferentes profissionais (assistente social, psicólogos...), incentivos a amamentação, à visita familiar. (C14)

Um desses aspectos diz respeito à articulação da equipe como facilitadora de uma atuação mais ampla no cuidado da criança.

Durante visitas, a equipe orienta quanto às consultas necessárias, vacinação, verifica a alimentação, os cuidados com a criança e, em reuniões, passa informações para todos os profissionais em busca de soluções. (I7)

Observei boa integração entre os profissionais das diversas áreas, o que contribui muito para maior resolutividade das questões de saúde. (C29)
Nesse sentido, para o alcance da integralidade, os profissionais devem, em conjunto, tomar consciência que o cuidado que prestam deve ser "totalizador, humanizado, contextualizado". Não somente os profissionais de saúde, como também os gestores devem fazer com que seja prioridade o foco no cuidado integral ao ser humano ${ }^{(22)}$.

\section{CONSIDERAÇÕES FINAIS}

A integralidade da assistência à criança é percebida pelos alunos de ambos os anos de graduação em Enfermagem como um cuidado inteiro, total, voltado à criança e sua família, considerando todos os aspectos relacionados à vida da criança e também às relações com o meio em que vive. Nos relatos dos alunos, observa-se um cuidado para além da questão física e do tratamento do corpo doente; está sim envolto em uma abordagem que considera o sujeito como ativo e cidadão, com direitos a serem respeitados.

A metodologia de ensino proposta pela instituição de ensino, cenário desse estudo, tem buscado proporcionar ao aluno a vivência precoce na realidade do mundo do trabalho como forma de estímulo à capacidade crítica e reflexiva do mesmo, com idas e vindas, para a construção de um conhecimento que faça sentido ao aluno, que analisa criticamente o que experiencia e intervém, de modo a tornar-se capaz de contribuir para a transformação da realidade.

Como forma de perceber a aplicação dos conhecimentos adquiridos acerca da integralidade do cuidado, os alunos trouxeram uma riqueza de exemplos de atuação, individual ou em conjunto com o professor/facilitador e com os profissionais dos serviços de saúde. Assim, depreende-se que os alunos conseguem perceber seu aprendizado e sua atuação de modo integrado e participativo.

Apesar de alguns relatos acerca da fragmentação da assistência prestada à criança nos serviços de saúde, o presente estudo demonstrou que as instituições de saúde caminham para um cuidado que integra, permite, participa e disponibiliza profissionais intencionados com a integralidade. $\mathrm{O}$ aluno, por sua vez, desmistifica o ideal de cuidado e se depara com o real. A partir desse encontro, o professor instiga o aluno a refletir sobre sua prática assistencial, para que esta faça sentido e seja apreendido o saber e o fazer relacionado à integralidade do cuidado da criança.

\section{REFERÊNCIAS}

1. Starfield B. Atenção primária: equilíbrio entre necessidades de saúde, serviços e tecnologia. Brasília: UNESCO, Ministério da Saúde; 2002.

2. Pinheiro R, Ferla A, Silva Júnior AG. Integrality in the population's health care programs. Ciênc e Saúde Coletiva 2007; 12(2):343-49.

3. Silva $K L$, Sena RR. Integralidade do cuidado na saúde: indicações a partir da formação do enfermeiro. Rev Esc
Enferm USP 2008;42(1):48-56.

4. Ministério da Educação (Brasil) Conselho Nacional de Educação. Câmara de Educação Superior. Resolução CNE/CES 3/2001. Institui as diretrizes curriculares nacionais do curso de Graduação em Enfermagem. Diário Oficial da união 23 dez 1996; Seção 1.

5. Xavier I, Fernandes JD, Ceribelli MIPF. Diretrizes curriculares: articulação do texto e do contexto. Bol Inf Assoc 
Bras Enferm 2002;44(2):6-7.

6. Universidade de São Paulo. Escola de Enfermagem de Ribeirão Preto. Proposta de reformulação curricular do curso de bacharelado em enfermagem: curso de enfermagem. Ribeirão Preto, 2004.

7. Minayo MCS. O desafio do conhecimento: pesquisa qualitativa em saúde. São Paulo: Hucitec- Abrasco; 2006.

8. Conselho Nacional de Saúde (Brasil) Resolução 196/96. Diretrizes e normas regulamentadoras de pesquisa envolvendo seres humanos. 1996.

9. Machado MFAS, Monteiro EMLM, Queiroz DT, Vieira NFC, Barroso MGT. Integralidade, formação de saúde, educação em saúde e as propostas do SUS - uma revisão conceitual. Ciênc e Saúde Coletiva 2007;12(2):335-42.

10. Rocha SMM, Lima RAG, Scochi CGS. Assistência integral à saúde da criança no Brasil: implicações para o ensino e a prática da enfermagem pediátrica. Saúde Soc 1997;6(1):25-52.

11. Semim GM, Souza MCBM, Corrêa AK. Professor como facilitador do processo ensino-aprendizagem: visão de estudante de enfermagem. Rev Gaúch Enferm 2009;30(3):484-91.

12. Lucchese R, Barros $S$. Pedagogia das competências para a transição paradigmática no ensino de enfermagem. Acta Paul Enferm 2006;19(1):92-9.

13. Scherer ZAP, Scherer EA, Carvalho AMP. Reflexões sobre o ensino da enfermagem e os primeiros contatos do aluno com a profissão. Rev Latinoam Enferm 2006;14(2):285-91.

14. Ferreira HM. A totalidade do conhecimento da enfermagem: uma abordagem curricular. Acta Paul Enferm
2003;16(1):56-65 .

15. Moretti-Pires RO, Bueno SMV. Freire e formação para o Sistema Único de Saúde: o enfermeiro, o médico e o odontólogo. Acta Paul Enferm 2009;22(4): 39-44.

16. Fernandes JD, Xavier IM, Ceribelli MIPF, Bianco MHC, Maeda D, Rodrigues MVC. Diretrizes curriculares e estratégias para implantação de uma nova proposta pedagógica. Rev Esc Enferm USP 2005;39(3):443-9.

17. Peres EM, Dal Poz MR, Grande NR. Visita domiciliar: espaço privilegiado para diálogo e produção de saberes. Rev Enferm UERJ 2006;14(2):208-13.

18. Egry EY, Fonseca RMGS. A família, a visita domiciliária e a enfermagem: revisitando o processo de trabalho da enfermagem em saúde coletiva. Rev Esc Enferm USP 2000;34(3):233-9.

19. Furtado MCC. Projeto Floresce uma Vida: potencialidades para o cuidado integral ao recém-nascido. Ribeirão Preto. Tese [Doutorado] - Escola de Enfermagem de Ribeirão Preto, Universidade de São Paulo; 2007.

20. Matsuda LM, Silva DMPP, Évora YDM, Coimbra JAH. Anotações/registros de enfermagem: instrumento de comunicação para a qualidade do cuidado?. Rev Eletrônica Enferm 2006;08(3):415-21.

21. Deves CE, Nunes DM. Desafio de ensinar a cuidar sob a ótica do aluno do curso de graduação em enfermagem. Rev Gaúch Enferm 2001;22(1):69-82.

22. Fontoura RT, Mayer CN. Uma breve reflexão sobre a integralidade. Rev Bras Enferm 2006;59(4):532-723.

23. Mattos RA. A integralidade na prática (ou sobre a prática da integralidade). Cad. Saúde Públ 2004;20(5): 1411-6. 